\title{
Synergistic effects of fibroblast growth factor-2 and bone morphogenetic protein-2 on bone induction
}

\author{
RONGYING SONG ${ }^{1}$, DINGDING WANG ${ }^{2}$, RONG ZENG $^{3}$ and $\mathrm{JU}^{\mathrm{W}} \mathrm{WNG}^{1}$ \\ ${ }^{1}$ Guangdong Provincial Key Laboratory of Bio-Engineering Medicine \\ (National Engineering Research Centre of Genetic Medicine), Guangzhou, Guangdong 510632; \\ ${ }^{2}$ Department of Biotechnology, College of Life Science and Bio-Pharmaceutical, Guangdong Pharmaceutical University, \\ Guangzhou, Guangdong 510006; ${ }^{3}$ Department of Materials Science and Engineering, College of \\ Chemistry and Materials, Jinan University, Guangzhou, Guangdong 510632, P.R. China
}

Received October 2, 2016; Accepted May 30, 2017

DOI: $10.3892 / \mathrm{mmr} .2017 .7183$

\begin{abstract}
The present study investigated the synergistic effect of co-administering fibroblast growth factor-2 (FGF-2) and bone morphogenetic protein-2 (BMP-2) on osteoblastic differentiation in $\mathrm{C} 2 \mathrm{C} 12$ cells and in rats. $\mathrm{C} 2 \mathrm{C} 12$ murine myoblast cells represent a well-accepted in vitro model system to study the ability of BMP-2 to alter cell lineage from the myogenic to the osteogenic phenotype. The osteoblastic differentiation potency was determined by alkaline phosphatase (ALP) and Alizarin red S staining. ALP activity and calcium concentrations were colorimetrically measured. Simultaneous administration of $4 \mu \mathrm{g} / \mathrm{ml}$ recombinant human BMP-2 with 2 ng/ml FGF-2 markedly enhanced ALP activity (an early marker of osteogenesis) of $\mathrm{C} 2 \mathrm{C} 12$ cells. This combination also increased extracellular signal-regulated kinase $1 / 2$ mitogen activated protein kinase signaling that is involved in the promoting effect of FGF-2 on BMP-2-induced osteoblastic differentiation in $\mathrm{C} 2 \mathrm{C} 12$ cells. Calcium deposition (a late marker of osteogenesis) and the expression of CD34 (a marker of new vessels) were promoted optimally by simultaneous local sustained administration of FGF-2 and BMP-2 using collagen and chitosan-coated antigen-extracted porcine cancellous implants in a rat ectopic implantation model. The synergistic effects of a combination of BMP-2 and FGF-2 may have potential for bone regenerative therapeutics.
\end{abstract}

\section{Introduction}

Tissue engineering has provided a promising strategy for improving bone regeneration by combining various types of

Correspondence to: Professor Ju Wang, Guangdong Provincial Key Laboratory of Bio-Engineering Medicine (National Engineering Research Centre of Genetic Medicine), 601 Huangpu Avenue (West), Guangzhou, Guangdong 510632, P.R. China

E-mail: wang_ju1688@163.com

Key words: bone morphogenetic protein, fibroblast growth factor, mitogen-activated protein kinase, osteogenesis, synergistic effect scaffolds, cells and growth factors (1-4). The bone healing process is a very complicated biological event involving a multitude of growth factors to regulate cellular responses and behaviors, including bone morphogenetic proteins (BMPs), fibroblast growth factor (FGF), vascular endothelial growth factor and platelet-derived growth factor (4). Thus, numerous efforts have been made to achieve bone regeneration by the controlled local delivery of single or dual growth factors combined with biomaterials $(5,6)$.

Recombinant human bone morphogenetic protein-2 (rhBMP-2) has been approved by the United States Food and Drug Administration for clinical applications (e.g., spinal fusion). However, the use of rhBMP-2 is limited clinically because of the very high doses needed that cause adverse effects including inflammation, edema and uncontrolled bone formation $(7,8)$.

FGF-2 is an important regulator for the proliferation, differentiation and migration of various cell types such as vascular cells and osteoblasts. Previous studies demonstrated the potential of FGF-2 in promoting bone regeneration and osseointegration (9-11). Thus, combined local delivery of FGF-2 and BMP-2 with biomaterials has attracted significant attention in promoting fracture healing and bone regeneration (12-14), However, there are some controversies about the synergistic effect of FGF-2 with BMP-2 on osteogenesis. In addition, dual local delivery of these growth factors may exhibit biphasic, stimulatory or inhibitory effects on bone regeneration depending on the timing, dosage and duration of the treatment $(15,16)$.

The exact molecular mechanisms of FGF-2/BMP-2 synergism remain unclear, and the local delivery mode of these growth factors when combined with biomaterials needs to be optimized to improve bone regeneration and meet the requirements of clinical application.

Collagen scaffold and chitosan-coated antigen-extracted porcine cancellous bone (APCB) are biocompatible. The structures and mechanic properties of APCB are similar to bone, and are good carriers for BMP-2 and FGF-2 releasing slowly and working effectively. Chitosan has several favorable physicochemical and biological characteristics such as biocompatibility, biodegradability, non-toxicity and 
film-forming properties, which can easily coat onto APCB to efficiently load BMP-2 and/or FGF-2, and release them in different releasing modes.

The present study selected $\mathrm{C} 2 \mathrm{C} 12$ myoblasts as an in vitro system, as this cell line is an established model for BMP-2 signaling. These cells fuse and form contractile myotubes in the absence of BMP-2, but commit to the osteogenic lineage upon BMP-2 exposure (17). In C2C12 cells, the optimal combination of FGF-2 and BMP-2 for osteoblast differentiation was determined by detecting the expression of alkaline phosphatase (ALP). Subsequently, the present study investigated the intracellular signaling pathways involved in FGF-2/BMP-2-induced osteogenic differentiation. Finally, the synergistic effects of FGF-2 and BMP-2 loaded into collagen- and chitosan-coated APCB were studied in a rat ectopic implantation model.

\section{Materials and methods}

Materials. Recombinant human (rh)BMP-2 was prepared as described previously (18). FGF-2 was purchased from Promega Corporation (Madison, WI, USA). High glucose Dulbecco's modified Eagle's medium (H-DMEM) and fetal bovine serum (FBS) were purchased from Thermo Fisher Scientific, Inc. (Waltham, MA, USA). All other culture reagents and type I collagen (COLL $\alpha 1)$ were purchased from Sigma-Aldrich (Merck KGaA, Darmstadt, Germany) and used without further purification. All primers used for the reverse transcription-quantitative polymerase chain reaction (RT-qPCR; Table I) were purchased from Invitrogen; Thermo Fisher Scientific, Inc. Rabbit anti-mothers against decapentaplegic (Smad) 1/5/8 (catalog no. sc-6031), rabbit anti-phosphorylated (p)-Smad1/5/8 (catalog no. sc-12353) and horseradish peroxidase-conjugated secondary antibodies (catalog no. sc-516087) were purchased from Santa Cruz Biotechnology, Inc. (Dallas, TX, USA). Rabbit anti-c-Jun N-terminal kinase (JNK; catalog no. 9252), anti-p38 (cat. no. 9212), p-p38 (catalog no. 9215) and anti- $\beta$-actin (catalog no.5057), and mouse anti-extracellular signal-regulated kinase (ERK) $1 / 2$ (catalog no. 4696), p-ERK1/2 (catalog no.9106) and p-JNK (catalog no. 4668) were purchased from Cell Signaling Technology, Inc. (Danvers, MA, USA).

Cells and culture conditions. Murine $\mathrm{C} 2 \mathrm{C} 12$ myoblasts were purchased from the American Type Culture Collection (Manassas, VA, USA). Cells were cultured in H-DMEM containing $10 \% \mathrm{FBS}$ with a $5 \% \mathrm{CO}_{2}$ atmosphere at $37^{\circ} \mathrm{C}$. After reaching confluence, the medium was replaced with H-DMEM containing 1\% FBS supplemented with rhBMP-2 or FGF-2, alone or together at different concentrations. Thereafter, cells were subjected to functional assays. Each experiment was performed independently three times.

ALP activity. Cells were harvested after 3 days of culture, washed twice with phosphate-buffered saline (PBS), and then lysed with lysis buffer $(0.1 \%$ Triton X-100, $50 \mathrm{mM}$ Tris, and $2 \mathrm{mM} \mathrm{MgCl}$ ). ALP activity in cell lysates was measured using an ALP Assay Kit (Beyotime, Nanjing, China) with p-nitrophenylphosphate as the chromogenic substrate, according to the manufacturer's protocol.
Western blotting. C2C12 cells were starved in DMEM containing $1 \%$ FBS for $\sim 12 \mathrm{~h}$, then cultivated in DMEM containing 10\% FBS supplemented with BMP-2 and FGF-2 alone or together at different concentrations for $30 \mathrm{~min}$. Equal amounts of protein $(20 \mu \mathrm{g})$ were subjected to SDS-PAGE and western blotting as described previously (19). Immunoreactive bands were visualized by an enhanced chemiluminescence reaction kit (Thermo Fisher Scientific, Inc.). Protein concentrations were determined by a Bicinchoninic Acid protein assay kit (Thermo Fisher Scientific, Inc.). Smad1/5/8 (1:500; catalog no. sc-6031; Santa Cruz Biotechnology, Inc.), p-Smad1/5/8 (1:500; catalog no. sc-12353; Santa Cruz Biotechnology, Inc.), ERK1/2 (1:1,000; catalog no. 4696; Cell Signaling Technology), p-ERK1/2 (1:1,000; catalog no. 9106; Cell Signaling Technology), JNK (1:1,000; catalog no. 9252; Cell Signaling Technology), p-JNK (1:1,000; catalog no. 4668; Cell Signaling Technology, Inc.), p38 (1:1,000; catalog no. 9212; Cell Signaling Technology, Inc.), and p-p38 (1:1,000; catalog no. 9215; Cell Signaling Technology, Inc.) primary antibodies were used, and incubated at $4^{\circ} \mathrm{C}$ for 12 h. $\beta$-actin $(1: 1,000$; catalog no. 4970; Cell Signaling Technology, Inc.) was used as an internal reference. Proteins were visualized and quantified relative to $\beta$-actin using an Alpha Imaging system (Willoughby, OH, USA). To test the effect of a mitogen-activated protein kinase (MAPK) inhibitor, cells were incubated with U0126 (ERK1/2 inhibitor, Cell Signaling Technology, Inc.) for $1 \mathrm{~h}$ prior to adding the growth factors. ERK1/2 phosphorylation and ALP activity were then measured.

$R N A$ extraction and $R T-q P C R$. According to the methods introduced by Sun et al (20), cells were harvested on day 7 after the various treatments. Total RNA was isolated by TRIzol extraction (Invitrogen; Thermo Fisher Scientific, Inc.) and reverse-transcribed to cDNA with a PrimeScript RT reagent kit (Takara Bio, Inc., Otsu, Japan) following the manufacturer's protocol. Expression of runt-related transcription factor 2 (RUNX2), sex-determining region $\mathrm{Y}$ (SRY)-box 9 (SOX9), osteocalcin (OC), osteopontin (OPN), and collagen $\alpha-1$ chain (COLL $\alpha 1)$ mRNA was determined using the SYBR Green (Toyobo Co., Ltd., Osaka, Japan) method with the primers listed in Table I. qPCR $\left(95^{\circ} \mathrm{C}\right.$ for $3 \mathrm{~min} ; 39$ cycles of $95^{\circ} \mathrm{C}$ for $30 \mathrm{sec}, 56^{\circ} \mathrm{C}$ for $15 \mathrm{sec}$, $72^{\circ} \mathrm{C}$ for $30 \mathrm{sec} ; 65^{\circ} \mathrm{C}$ for $5 \mathrm{sec}$; and $95^{\circ} \mathrm{C}$ for $5 \mathrm{sec}$ ) was performed using a Rotor Gene 6000 RT-PCR machine (Corbett Life Sciences, Mortlake, Australia). $\beta$-Actin served as the normalization factor and relative gene expression was expressed as the 'fold-change', calculated using the $2^{-\Delta \Delta \mathrm{C} \text { q }}$ method (21).

Alizarin Red $S$ staining. $\mathrm{C} 2 \mathrm{C} 12$ cells $\left(1 \times 10^{4}\right.$ cells $\left./ \mathrm{cm}^{2}\right)$ were cultured in 24-well plates in H-DMEM containing 10\% FBS supplemented with rhBMP-2 or FGF-2 $(0,2$ or $4 \mathrm{ng} / \mathrm{ml})$ alone or in combination. After a 4-week incubation, cells were washed with PBS and fixed with 70\% ice-cold ethanol in PBS for $1 \mathrm{~h}$. The fixed cells were stained with $10 \mathrm{mg} / \mathrm{ml}$ Alizarin Red S for $15 \mathrm{~min}$ at room temperature, then washed with distilled water and PBS. The dried stained cells were observed under a light microscope (Olympus Corporation, Tokyo, Japan) equipped with a digital camera. 
Table I. Sequence of primers used for reverse transcription-quantitative polymerase chain reaction assay.

\begin{tabular}{|c|c|c|c|}
\hline Target gene & Primer & Sequence $\left(5^{\prime}-3^{\prime}\right)$ & Product size (bp) \\
\hline \multirow[t]{2}{*}{ SOX9 } & Forward & GGCCGAAGAGGCCACGGAAC & \multirow[t]{2}{*}{182} \\
\hline & Reverse & TGCCAGCTTGCACGTCGGTT & \\
\hline \multirow[t]{2}{*}{ OPN } & Forward & TGAGGCTGCAGTTCTCCTGGC & \multirow[t]{2}{*}{190} \\
\hline & Reverse & GGGTCAGGCACCAGCCATGT & \\
\hline \multirow[t]{2}{*}{ COLLa1 } & Forward & CCTGAGTCAGCAGATTGA & \multirow[t]{2}{*}{106} \\
\hline & Reverse & TCCGCTCTTCCAGTCAG & \\
\hline \multirow[t]{2}{*}{ RUNX2 } & Forward & GCCAACAAGAGCAGGGAAGGC & \multirow[t]{2}{*}{146} \\
\hline & Reverse & CTGGCCTGGATTAGGAAGCCAC & \\
\hline \multirow[t]{2}{*}{$\mathrm{OC}$} & Forward & TGAGGACCATCTTTCTGCTCAC & \multirow[t]{4}{*}{153} \\
\hline & Reverse & CAAGGTAGCGCCGGAGTC & \\
\hline \multirow[t]{2}{*}{$\beta$-actin } & Forward & TGCCCAGAAAATGAAAAAGG & \\
\hline & Reverse & GGATGACACAGCGTGAGAGA & \\
\hline
\end{tabular}

RUNX2, runt-related transcription factor 2; SOX9, sex-determining region Y (SRY)-box 9; OC, osteocalcin; OPN, osteopontin; COLL 1 1, collagen $\alpha-1$ chain.

Preparation of growth factor-loaded implants. PBS (0.01 M), and solutions of COLL $\alpha 1(5 \mathrm{~g} / \mathrm{l}), \mathrm{rhBMP}-2(0.4 \mathrm{mg} / \mathrm{ml})$ and FGF-2 $(0.2 \mu \mathrm{g} / \mathrm{ml})$ were used to prepare collagen sponges loaded with different concentrations of growth factors by simple mixing. These sponges were used to assess ectopic bone formation in five groups, as presented in Table II. Using a well from a 96-well plate as the mold, samples were lyophilized and sterilized by ${ }^{60} \mathrm{Co}$ irradiation, then stored at $-20^{\circ} \mathrm{C}$ before use.

To investigate the optimal timing of combined rhBMP-2 and FGF-2 treatment to enhance osteogenesis, $10.0 \pm 0.5 \mathrm{mg}$ APCB (Guanhao Biotech Co., Ltd., Guangzhou, China), with a porosity up to $85 \%$ and compression modulus of $13.44 \mathrm{MPa}$, was used. rhBMP-2 and/or FGF-2 were loaded in different modes by adsorbing the rhBMP-2 $(0.1 \mathrm{mg} / \mathrm{ml})$ and/or FGF-2 $(0.05 \mu \mathrm{g} / \mathrm{ml})$ solutions with or without co-deposition of chitosan $(1 \mathrm{mg} / \mathrm{ml})$ in sequences shown in Table III. The loaded amounts of growth factors (determined by an enzyme-linked immunosorbent assay) were 2.2 $\pm 0.2 \mu \mathrm{g}$ for rhBMP-2 and $1.2 \pm 0.1 \mathrm{ng}$ for FGF-2.

Animal surgery. All animal experiments were performed according to a protocol approved by the Animal Ethical Committee of Jinan University (Jinan, China). Male Kunming Sprague-Dawley rats (8-10 weeks old; weight, 280-320 g; humidity, $70 \%$; temperature, $25^{\circ} \mathrm{C}$; 12 -h light/dark cycle; $\mathrm{n}=48$ ) were obtained from the Laboratory Animal Center, Sun Yat-Sen University, and housed in cages with free access to food and water for 1 week. Rats were divided equally into 12 groups (Tables II and III), and the ectopic implantation model was established. Ectopic bone formation by collagen (Table II) or chitosan-coated APCB implants loaded with different dosages of growth factors (Table III) was assessed under standard sterile conditions. Implants were placed into the peroneal space of the peroneus muscle on both sides of rats anesthetized with pentobarbital sodium $(35-40 \mathrm{mg} / \mathrm{kg}$ body weight; Sigma-Aldrich; Merck KGaA). The incision site was stapled shut. Intermuscular spaces of rats in the control
Table II. Ectopic bone formation by collagen experimental groups, as tested in vivo.

\begin{tabular}{lcc}
\hline Group & FGF-2 (ng) & BMP-2 $(\mu \mathrm{g})$ \\
\hline 1 & - & - \\
2 & 2 & - \\
3 & - & 4 \\
4 & 2 & 4 \\
5 & 4 & 4 \\
\hline
\end{tabular}

BMP-2, bone morphogenic protein-2; FGF-2, fibroblast growth factor-2.

group were separated with collagen or APCB only. A total of 4 weeks post-implantation, rats were euthanized by cervical dislocation and parts of the peroneus muscle implanted with specimen were removed for sampling and subjected to further analysis.

Calcium content assay. Samples were washed twice with PBS and incubated with $1 \mathrm{ml} 0.6 \mathrm{~mol} / 1 \mathrm{HCl}$ for $24 \mathrm{~h}$ at room temperature to extract calcium. After centrifugation at $1,000 \mathrm{x} g$ for $5 \mathrm{~min}$, the calcium concentrations in the supernatants were measured by the ortho-cresolphthalein complex one method using a Calcium Colorimetric Assay kit (BioSino Bio-Technology and Science, Inc., Beijing, China).

Histology and immunohistochemistry. Samples were fixed in $10 \%$ neutral buffered formalin, decalcified, dehydrated in graded ethanol solutions, embedded in paraffin and cut into sections (4- $\mu \mathrm{m}$ thick). Certain sections were stained with hematoxylin and eosin (at room temperature for $5 \mathrm{~min}$ ) for histological study. For immunohistochemistry, rabbit monoclonal anti-ALP (1:1,000; cat. no. P06115), anti-CD34 (1:1,000; cat. no. PB0031) and anti-OC antibodies (1:1,000; cat. no. PB0074) 
Table III. Experimental groups with chitosan-coated APCB implants as tested in vivo.

\begin{tabular}{lll}
\hline Group & \multicolumn{1}{c}{ Implants } & \multicolumn{1}{c}{ Note } \\
\hline 1 & Blank APCB/CS & Chitosan-coated APCB without growth factors \\
2 & APCB/(BMP-2/FGF-2) & $\begin{array}{l}\text { APCB with both BMP-2 and FGF-2 loaded directly } \\
\text { Chitosan-coated APCB with both BMP-2 and FGF-2 encapsulated in chitosan layer } \\
\text { Chitosan-coated APCB with FGF-2 encapsulated in chitosan layer and then BMP-2 } \\
\text { loaded directly }\end{array}$ \\
$\begin{array}{lll}\text { Chitosan-coated APCB with BMP-2 encapsulated in chitosan layer and then FGF-2 } \\
\text { loaded directly }\end{array}$ \\
APCB/CS(FGF-2)/BMP-2 & Chitosan-coated APCB with BMP-2 encapsulated in chitosan layer \\
7 & APCB/CS(BMP-2)/FGF-2 & Chitosan-coated APCB with FGF-2 encapsulated in chitosan layer \\
\hline
\end{tabular}

BMP-2, bone morphogenic protein-2; FGF-2, fibroblast growth factor-2; APCB, antigen-extracted porcine cancellous bone; CS, chitosan-coated .

(all Wuhan Boster Biological Technology, Ltd., Wuhan, China) were used at $4^{\circ} \mathrm{C}$ for $12 \mathrm{~h}$. Images were captured under a Leica DMRA2 microscope (Leica Microsystems GmbH, Wetzlar, Germany).

Statistical analysis. All data are presented as the mean \pm standard deviation. Statistical analysis was performed by one-way analysis of variance using SPSS 13.0 software (SPSS, Inc., Chicago, IL, USA) followed by post hoc procedures based on modified Student-Newman-Keuls tests. $\mathrm{P}<0.05$ was considered to indicate a statistically significant difference.

\section{Results}

Effects of different combinations of rhBMP-2 and FGF-2 on osteoblastic differentiation of $C 2 C 12$ cells. ALP activity was measured as an early marker of osteoblastic differentiation to determine the optimal combination of FGF-2 and rhBMP-2 to induce the conversion of $\mathrm{C} 2 \mathrm{C} 12$ cells from myoblasts to osteoblasts. In the present study, ALP activity was measured after treatment with rhBMP-2 and FGF-2 for 3 days. Treatment duration was also extended to 5 and 7 days (data not shown). Although ALP activity was higher after a longer induction with rhBMP-2 and FGF-2, the most effective dose was the same at days 3,5 and 7. Therefore, only the results for day 3 are presented.

The results revealed that rhBMP-2 markedly enhanced the ALP activity of $\mathrm{C} 2 \mathrm{C} 12$ cells after 3 days in a dose-dependent manner. The largest increase was detected in the $4 \mu \mathrm{g} / \mathrm{ml}$ group (Fig. 1A). Low-dose FGF-2 (2 ng/ml) also stimulated ALP activity, which was statistically significant compared with the control (Fig. 1B).

To assess the effect of combined treatments, FGF-2 $(0,2$ and $4 \mathrm{ng} / \mathrm{ml}$ ) was added to the culture medium 0,24 and $48 \mathrm{~h}$ post $4 \mu \mathrm{g} / \mathrm{ml}$ rhBMP-2 treatment. Maximum ALP activity was observed when $4 \mu \mathrm{g} / \mathrm{ml}$ rhBMP-2 and $2 \mathrm{ng} / \mathrm{ml} \mathrm{FGF-2} \mathrm{were}$ given simultaneously (Fig. 1C). The results indicated that both the dosage and timing of FGF-2 treatment may serve key roles in promoting rhBMP-2-induced osteoblastic differentiation of C2C12 cells.

Alizarin Red S staining was used to visualize calcium deposits as the end marker of osteoblastic differentiation in
$\mathrm{C} 2 \mathrm{C} 12$ cells after 4 weeks of induction. Compared with the control (Fig. 2A), cells induced by FGF-2 alone ( 2 and $4 \mathrm{ng} / \mathrm{ml}$ ) exhibited little calcium accumulation (Fig. 2B and C, respectively). In contrast, cells induced by rhBMP-2 ( $4 \mu \mathrm{g} / \mathrm{ml})$ alone, or rhBMP-2 combined simultaneously with FGF-2 (2 or $4 \mathrm{ng} / \mathrm{ml}$ ), demonstrated significant calcium deposits (Fig. 2D, $\mathrm{E}$, and $\mathrm{F}$, respectively). The highest level of mineralization was observed in cells induced by $4 \mu \mathrm{g} / \mathrm{ml} \mathrm{rhBMP}-2$ and $2 \mathrm{ng} / \mathrm{ml}$ FGF-2. This was consistent with the results of the ALP assay (Fig. 1).

Signaling pathways involved in osteogenic differentiation induced by the simultaneous administration of FGF-2 and rhBMP-2. rhBMP-2 induces bone regeneration through a Smad-dependent canonical pathway, though it is not clear whether Smad-independent MAPK pathways are also involved. The results of the present study demonstrated that $4 \mu \mathrm{g} / \mathrm{ml}$ rhBMP-2 significantly activated (i.e., phosphorylated) Smad1/5/8, while p-Smad1/5/8 levels were independent of co-treatment with 2 or $4 \mathrm{ng} / \mathrm{ml}$ of FGF-2 (Fig. 3A). Additionally, FGF-2 stimulated the phosphorylation of ERK1/2, p38 and JNK with or without the presence of 2 or $4 \mu \mathrm{g} / \mathrm{ml}$ rhBMP-2 (Fig. 3B, C and D, respectively). However, in the presence of rhBMP-2, an increase of p-ERK1/2 and p-p38, but not p-JNK, was observed. The phosphorylation of ERK1/2 was the highest at $2 \mathrm{ng} / \mathrm{ml}$ FGF-2 in the presence of $4 \mu \mathrm{g} / \mathrm{ml} \mathrm{rhBMP}-2$. However, the phosphorylation of $\mathrm{p} 38$ activated by the combination of FGF-2 and rhBMP-2 was the same as rhBMP-2 alone. This suggested that rhBMP-2 served a synergistic role in the activation of ERK1/2 by FGF-2.

The activity of ALP in C2C12 cells induced by rhBMP-2 combined with FGF-2 was inhibited to the same level by pre-treatment with the ERK1/2 inhibitor, U0126 (Fig. 4). This indicated that ERK1/2 MAPK signaling was involved in the promoting effect of FGF-2 on rhBMP-2-induced osteoblastic differentiation in $\mathrm{C} 2 \mathrm{C} 12$ cells.

Promoting effect of FGF-2 on rhBMP-2-induced osteogenic gene expression in $\mathrm{C} 2 \mathrm{Cl} 2$ cells. The mRNA expression levels of osteoblastic differentiation markers including SOX9, RUNX2, OPN, OC and COLL $\alpha 1$ were quantified by RT-qPCR after 7 days of induction with rhBMP-2 and FGF-2, alone or 
A

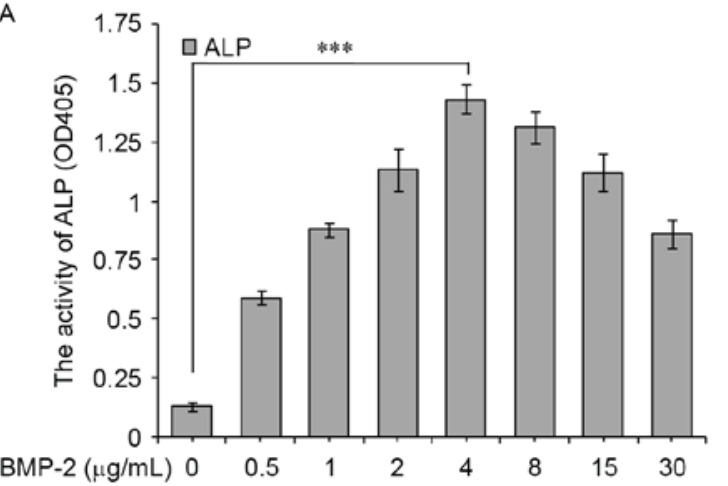

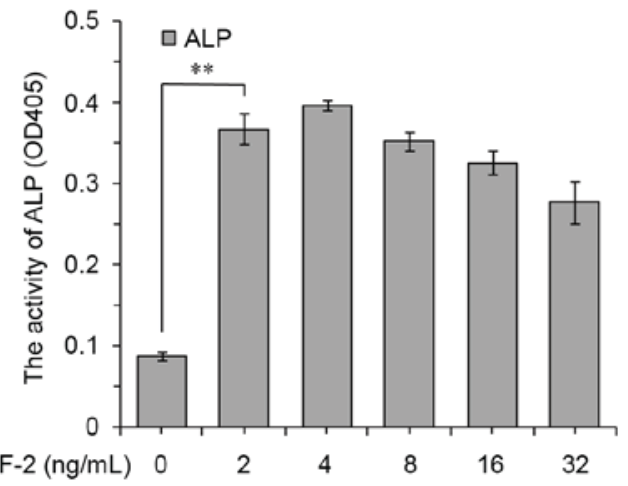

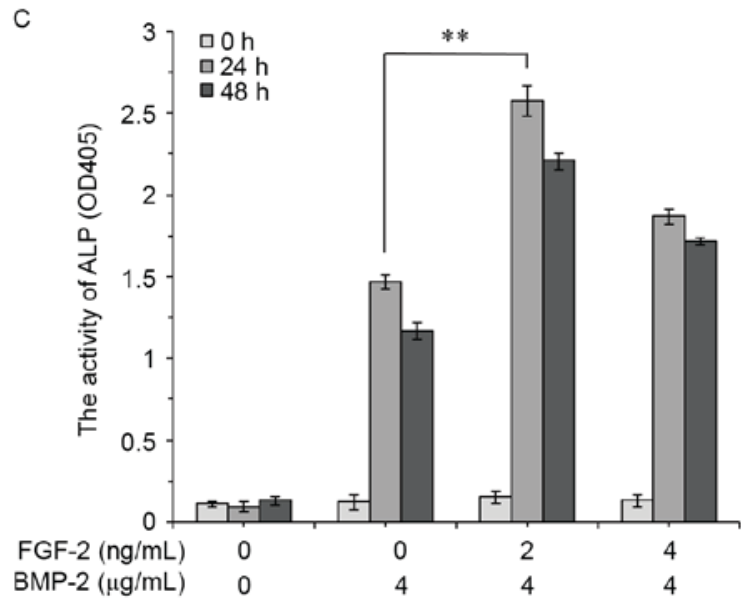

Figure 1. ALP activity in $\mathrm{C} 2 \mathrm{C} 12$ cells. C2C12 cells were cultured for 3 days with various concentrations of (A) BMP-2, (B) FGF-2 or (C) FGF-2 (0, $2,4 \mathrm{ng} / \mathrm{ml})$ added 0,24 or $48 \mathrm{~h}$ after BMP-2 $(4 \mu \mathrm{g} / \mathrm{ml})$. Data are expressed as the mean \pm standard deviation $(\mathrm{n}=12) .{ }^{* *} \mathrm{P}<0.01,{ }^{* * * *} \mathrm{P}<0.001$. ALP, alkaline phosphatase; BMP-2, bone morphogenic protein-2; FGF-2, fibroblast growth factor-2; OD, optical density.

A

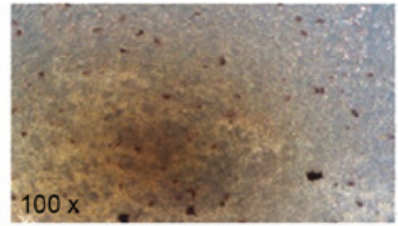

$\begin{array}{ll}\text { FGF-2 }(\mathrm{ng} / \mathrm{ml}) & 0 \\ \text { BMP-2 }(\mu \mathrm{g} / \mathrm{ml}) & 0\end{array}$

$\mathrm{D}$

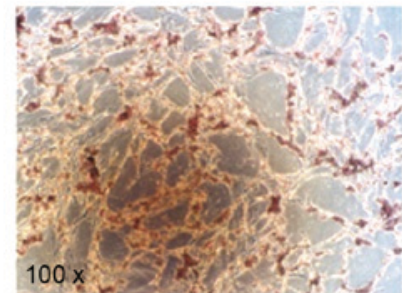

FGF-2 (ng/ml) $\mathrm{BMP}-2(\mu \mathrm{g} / \mathrm{ml})$
B

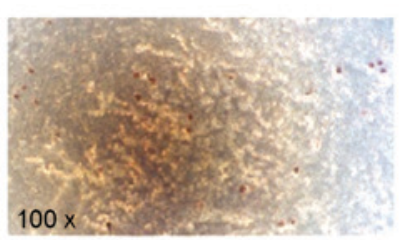

2

E

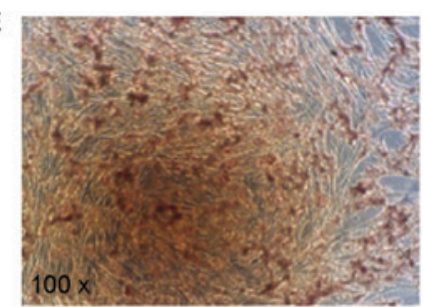

2

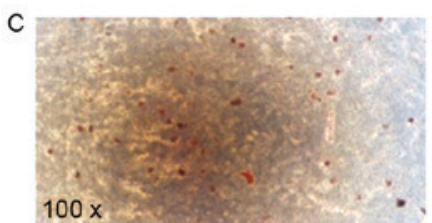

4

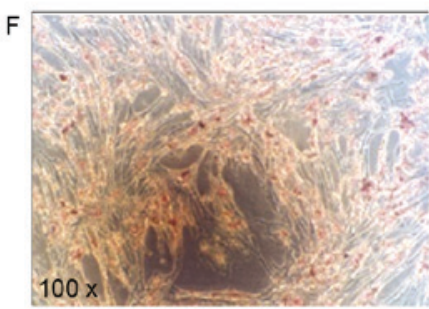

4

Figure 2. Alizarin Red S staining of calcium deposits in C2C12 cells. C2C12 cells were cultured for 4 weeks with (A) no additions (control group), (B) FGF-2 $(2 \mathrm{ng} / \mathrm{ml}),(\mathrm{C})$ FGF-2 (4 ng/ml), (D) BMP-2 (4 $\mu \mathrm{g} / \mathrm{ml})$, (E) BMP-2 (4 $\mu \mathrm{g} / \mathrm{ml})+$ FGF-2 $(2 \mathrm{ng} / \mathrm{ml})$, and (F) BMP-2 (4 $\mu \mathrm{g} / \mathrm{ml})+$ FGF-2 (4 ng/ml). Magnification, x100 . BMP-2, bone morphogenic protein-2; FGF-2, fibroblast growth factor-2.

in combination. FGF-2 significantly enhanced the expression levels of all markers, except SOX9, in a dose-dependent manner (Fig. 5). The induction was greatest with the combined treatment of $4 \mu \mathrm{g} / \mathrm{ml} \mathrm{rhBMP}-2$ and $2 \mathrm{ng} / \mathrm{ml}$ FGF-2, consistent with the other results.
Ectopic osteogenesis. A total of 4 weeks post-implantation, rats were euthanized by cervical dislocation, and the parts of the peroneus muscle implanted with specimen were excised and subjected to further analysis. The amount of calcium deposited in the rat peroneus muscle was measured as described 


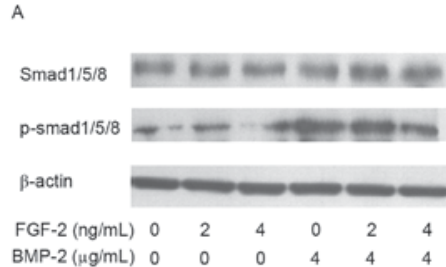

B

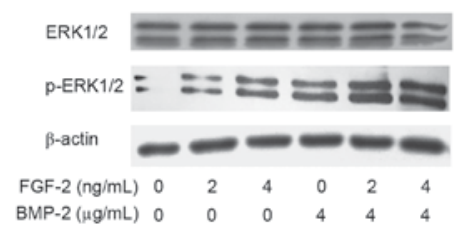

C

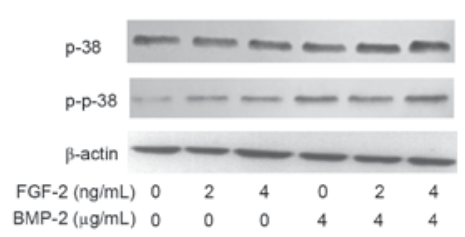

$D$

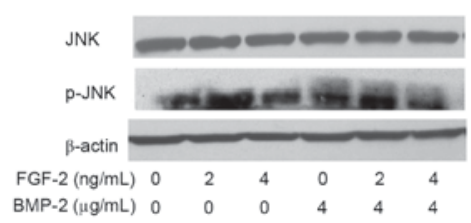

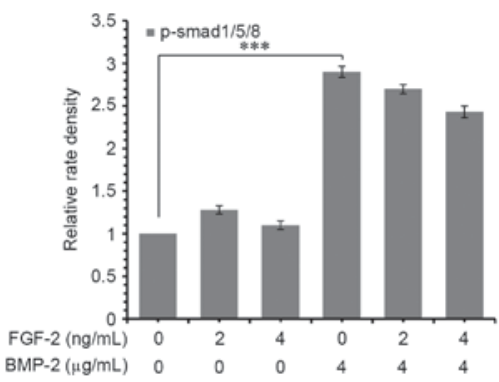
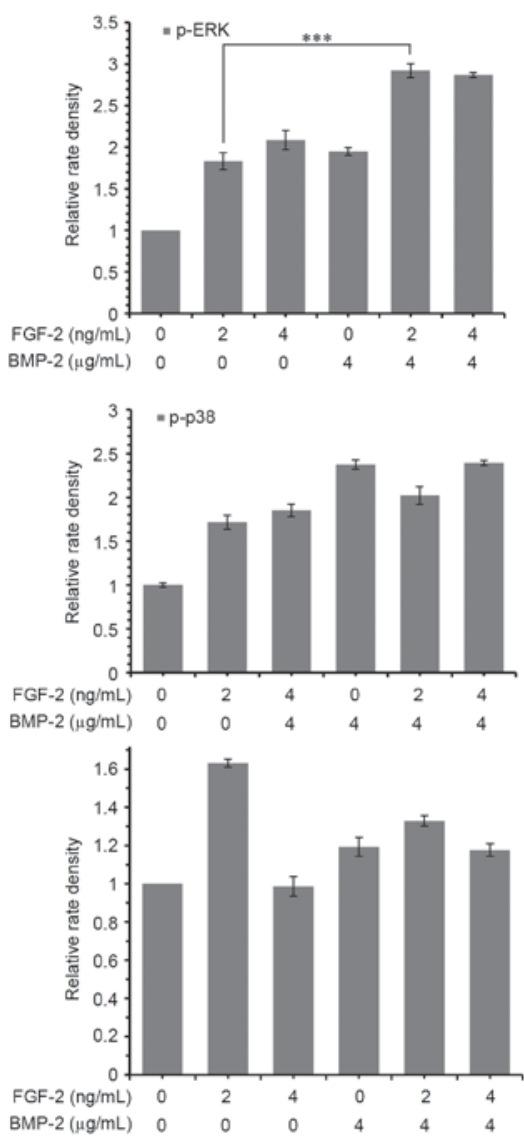

Figure 3. Signaling pathways involved in osteogenic differentiation. Phosphorylation of (A) Smad1/5/8, (B) ERK1/2, (C) p38 and (D) JNK in C2C12 cells, determined by western blotting. Cells were treated with or without different concentrations of BMP-2 and FGF-2, alone or in combination. Data are expressed as the mean \pm standard deviation $(\mathrm{n}=12)$. ${ }^{* * *} \mathrm{P}<0.001$. BMP-2, bone morphogenic protein-2; FGF-2, fibroblast growth factor-2; Smad, mothers against decapentaplegic; ERK, extracellular signal-regulated kinase; JNK, c-Jun N-terminal kinase; p, phosphorylated.

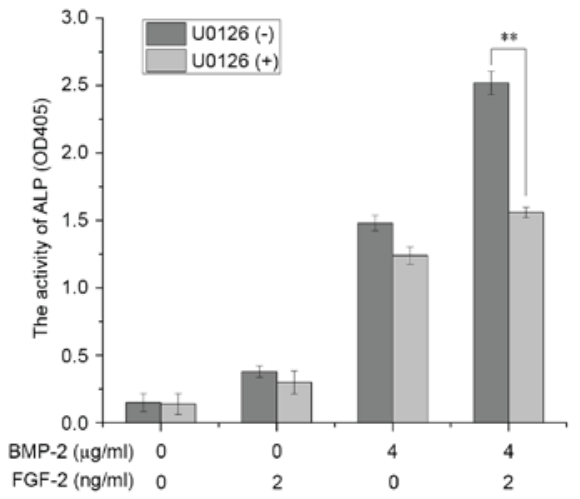

Figure 4. Effect of the ERK1/2 inhibitor, U0126, on ALP activity in C2C12 cells. $\mathrm{C} 2 \mathrm{C} 12$ cells were cultured for 3 days in the presence or absence of different concentrations and combinations of BMP-2 and FGF-2. Data are expressed as the mean \pm standard deviation $(n=12) .{ }^{* *} \mathrm{P}<0.01$. BMP-2, bone morphogenic protein-2; FGF-2, fibroblast growth factor-2; OD, optical density; ALP, alkaline phosphatase; ERK, extracellular signal-regulated kinase. previously (22). After 4 weeks, calcium deposition was significantly higher in the groups with implants containing both rhBMP-2 and FGF-2 compared with groups with implants containing rhBMP-2 or FGF-2 alone (Fig. 6A). The dose of FGF-2 (2 ng) combined with rhBMP-2 (4 $\mu \mathrm{g})$ demonstrated the greatest increase in bone formation. In addition, hematopoietic tissue was obviously formed in rats implanted with the combination (Fig. 6B).

The optimal combination mode to enhance osteogenesis was determined using chitosan-coated APCB with controlled timing and release rate of rhBMP-2 and FGF-2. The maximum calcium concentration was observed in group 3 [APCB/CS (BMP-2/FGF-2)] composite material $(\mathrm{P}<0.05)$, indicating that the sustained release of rhBMP-2 and FGF-2 simultaneously yielded the highest osteogenic efficiency (Fig. 7). Based on the cycle time of new bone formation and mineralization, it was concluded that the sustained simultaneous release of rhBMP-2 

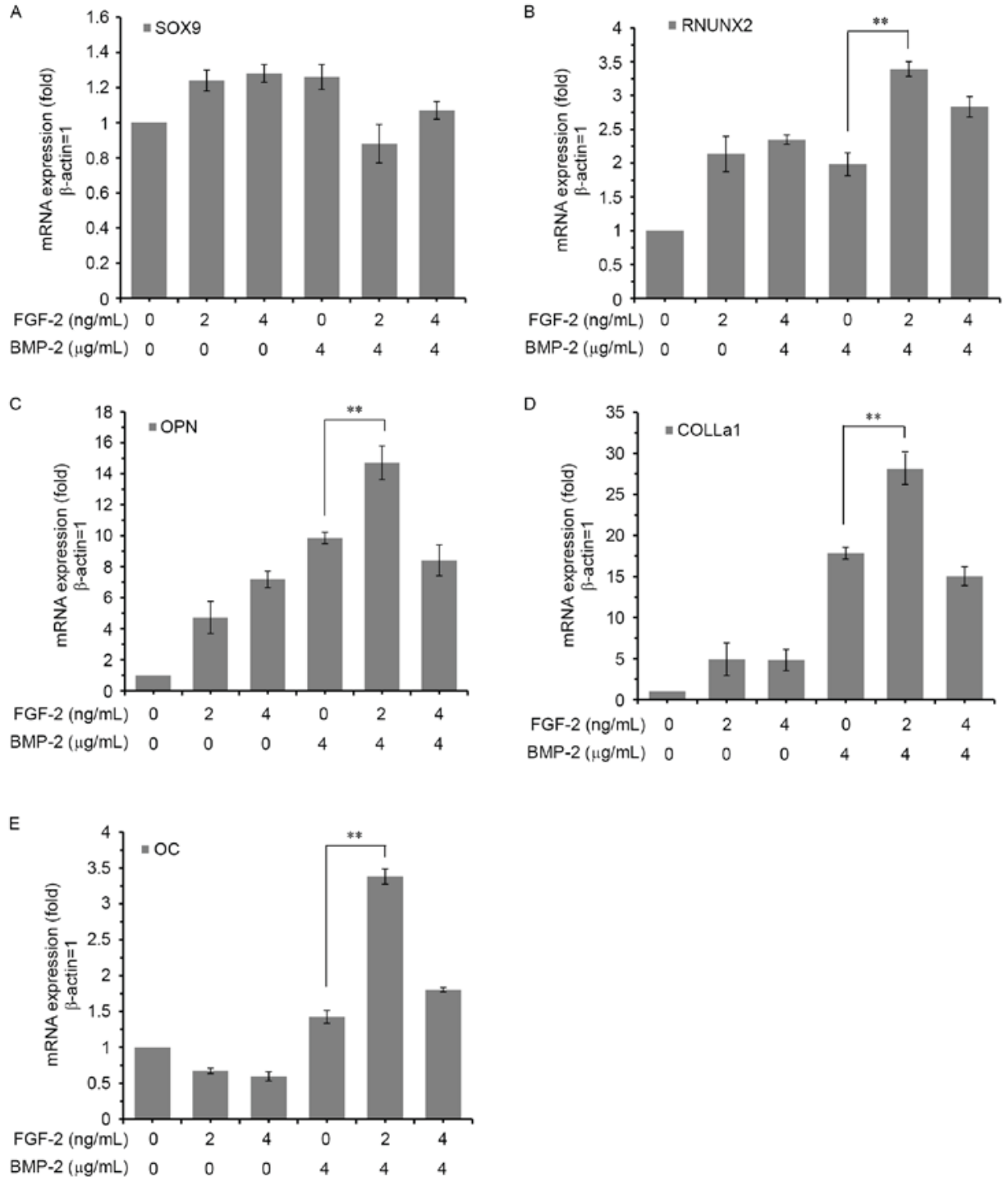

Figure 5. Effect of FGF-2 on BMP-2-induced osteogenic gene expression in C2C12 cells. C2C12 cells were cultured for 7 days with or without different concentrations and combinations of BMP-2 and FGF-2. The mRNA expression levels of (A) SOX9, (B) RUNX2, (C) OPN, (D) COLL $\alpha 1$ and (E) OC were determined by reverse transcription-quantitative polymerase chain reaction. The expression of each gene was normalized to the level in $\mathrm{C} 2 \mathrm{C} 12$ cells cultured without FGF-2 and BMP-2. Data are expressed as the mean \pm standard deviation $(\mathrm{n}=12)$. ${ }^{* *} \mathrm{P}<0.01$. BMP-2, bone morphogenic protein-2; FGF-2, fibroblast growth factor-2; RUNX2, runt-related transcription factor 2; SOX9, sex-determining region Y (SRY)-box 9; OC, osteocalcin; OPN, osteopontin; COLL $\alpha 1$, collagen $\alpha-1$ chain.

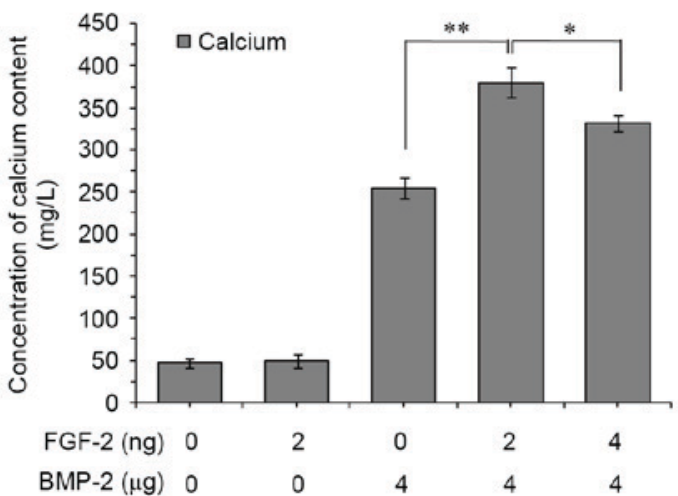

B

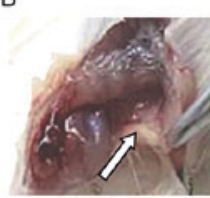

Blank collagen

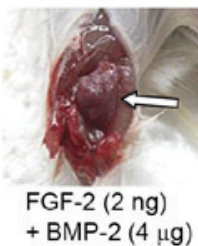

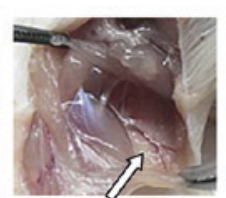

FGF-2 (2 ng)

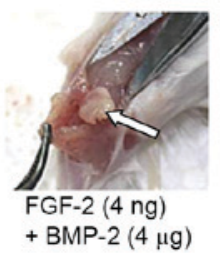

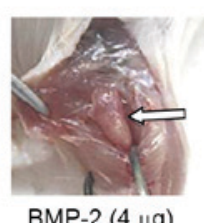

BMP-2 $(4 \mu \mathrm{g})$

Figure 6. Calcium deposition induced by collagen implants. (A) Calcium deposition and (B) specimens at 4 weeks after implantation. Collagen implants were loaded with FGF-2 (2 ng), BMP-2 (4 $\mu \mathrm{g})$, FGF-2 (2 ng) + BMP-2 (4 $\mu \mathrm{g})$ and FGF-2 (4 ng) + BMP-2 (4 $\mu \mathrm{g})$. Implants were placed under the skin at the inner side of the peroneus muscle on both sides of the rats. The collagen only group served as the control. Data are expressed as the mean \pm standard deviation ( $\mathrm{n}=12$ ). ${ }^{*} \mathrm{P}<0.05,{ }^{* *} \mathrm{P}<0.01$. BMP-2, bone morphogenic protein-2; FGF-2, fibroblast growth factor-2. 


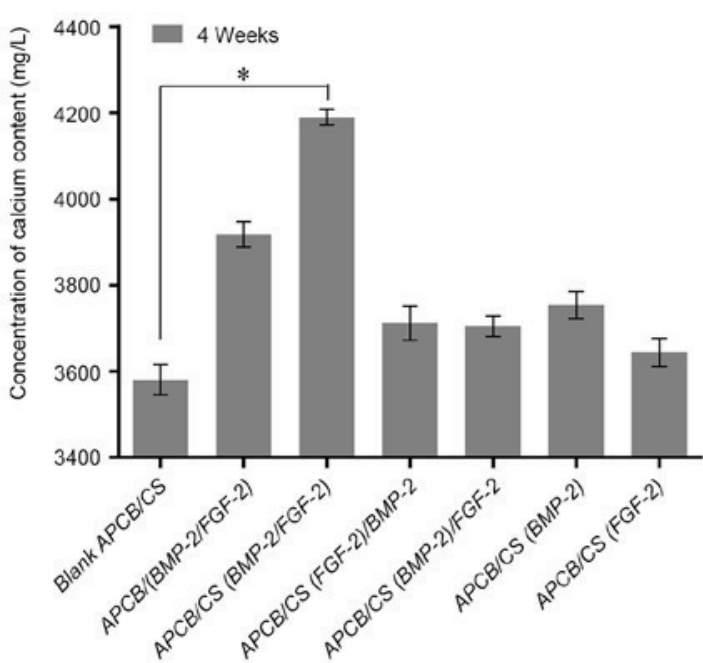

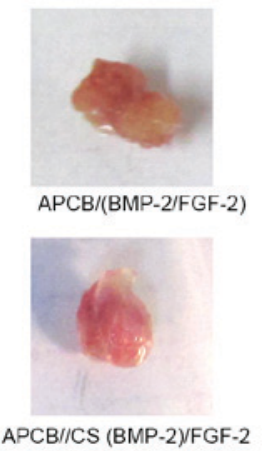

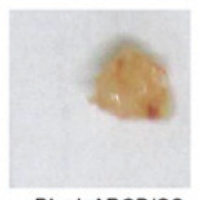

Blank APCB/CS
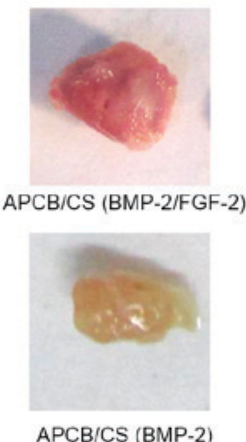

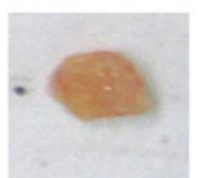

APCB/CS (FGF-2)/BMP-2

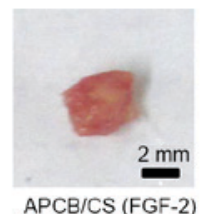

Figure 7. Calcium deposition induced by sustained-release APCB implants. (A) Calcium deposition and (B) specimens at 4 weeks after implantation. There were 7 chitosan-coated APCB groups: 1, blank APCB/CS, chitosan-coated APCB without growth factors; 2, APCB/(BMP-2/FGF-2), APCB with both BMP-2 and FGF-2 loaded directly; 3, APCB/CS(BMP-2/FGF-2), chitosan-coated APCB with both BMP-2 and FGF-2 encapsulated in the chitosan layer; 4, APCB/CS (FGF-2)/BMP-2, chitosan-coated APCB with FGF-2 encapsulated in the chitosan layer and then BMP-2 loaded directly; 5, APCB/CS(BMP-2)/FGF-2, chitosan-coated APCB with BMP-2 encapsulated in the chitosan layer and then FGF-2 loaded directly; 6, APCB/CS(BMP-2), chitosan-coated APCB with BMP-2 encapsulated in the chitosan layer; 7, APCB/CS(FGF-2), chitosan-coated APCB with FGF-2 encapsulated in the chitosan layer. Data are expressed as the mean \pm standard deviation $(\mathrm{n}=12)$. ${ }^{*} \mathrm{P}<0.05$. BMP-2, bone morphogenic protein-2; FGF-2, fibroblast growth factor-2; APCB, antigen-extracted porcine cancellous bone; CS, chitosan-coated.

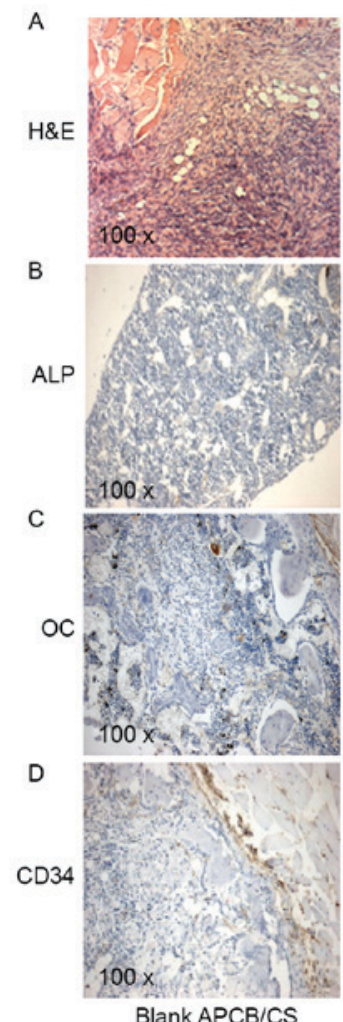

Blank APCB/CS
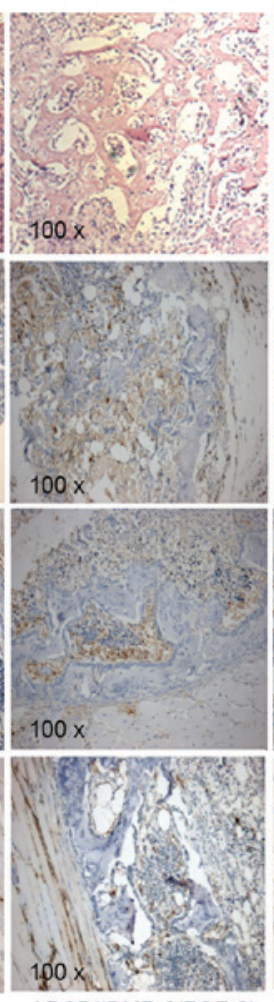

$\mathrm{APCB} /(\mathrm{BMP}-2 / \mathrm{FGF}-2)$
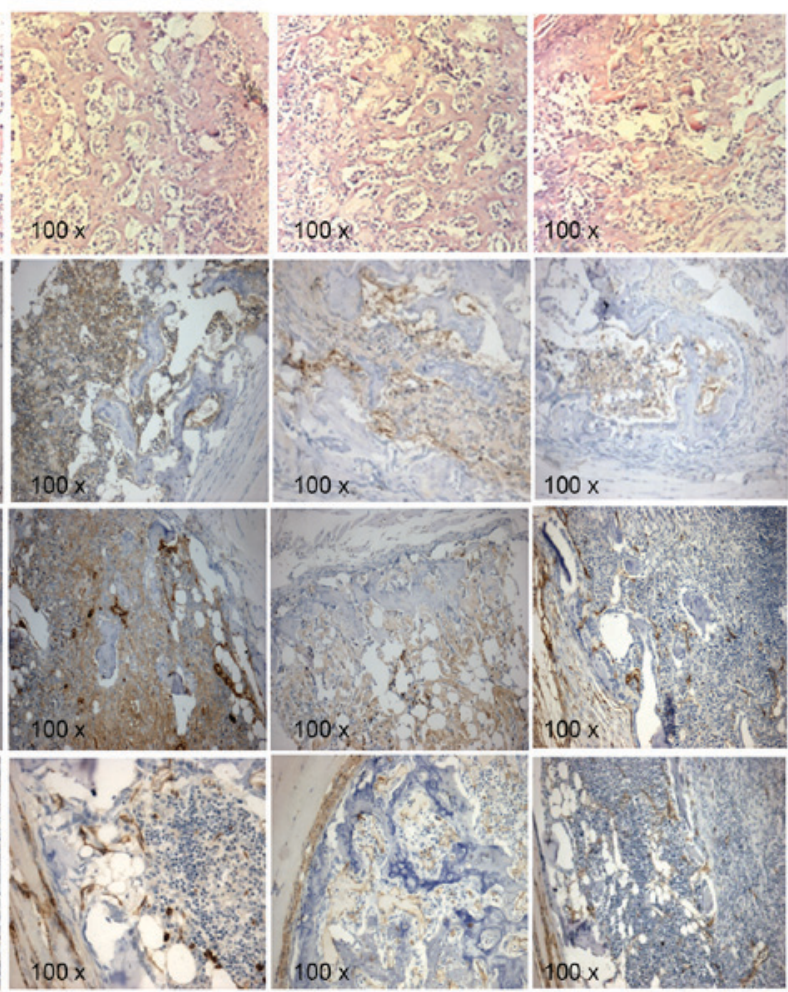

$\mathrm{APCB} / \mathrm{CS}(\mathrm{BMP}-2 / \mathrm{FGF}-2)$
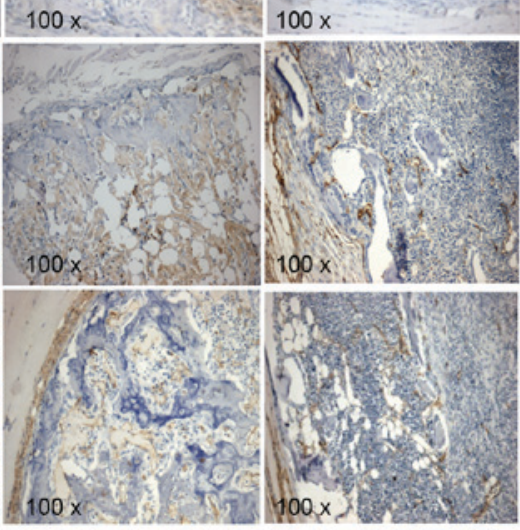

$\mathrm{APCB} / \mathrm{CS}(\mathrm{BMP}-2)$

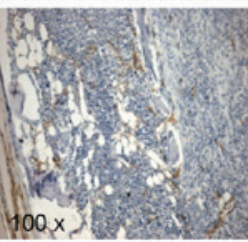

$\mathrm{APCB} / \mathrm{CS}$ (FGF-2)

Figure 8. Effects of FGF-2 and BMP-2 on new bone formation. (A) H\&E staining. Immunohistochemical analysis of ectopic bones for the expression of (B) ALP, (C) OC and (D) CD34. Analyses were performed on ectopic bones from rats treated with control APCB/CS, APCB/(BMP-2/FGF-2), APCB/CS (BMP-2/FGF-2), APCB/CS(BMP-2) and APCB/CS(FGF-2). Magnification, x100. BMP-2, bone morphogenic protein-2; FGF-2, fibroblast growth factor-2; APCB, antigen-extracted porcine cancellous bone; CS, chitosan-coated; ALP, alkaline phosphatase; OC, osteocalcin; CD34, cluster of differentiation 34; $\mathrm{H} \& \mathrm{E}$, hematoxylin and eosin.

and FGF-2 was optimal for inducing osteogenesis in porous materials.
FGF-2 promotes the expression of osteogenic markers and angiogenesis in rhBMP-2-induced ectopic bone.Histologically, 
FGF-2 had a promoting effect upon rhBMP-2-induced ectopic bone in vivo. The combination of FGF-2 and rhBMP-2 enhanced osteogenesis compared with controls (Fig. 8A); mature trabecular bone with bone marrow was recognizable, and there was an increased amount of bone per high-power field. Immunohistochemistry demonstrated that ALP was expressed in implants loaded with rhBMP-2 and FGF-2, alone or in combination (Fig. 8B). ALP expression was higher in the APCB/(BMP-2/FGF-2) group compared with either rhBMP-2 or FGF-2 treatment alone. Furthermore, ALP expression was highest in the APCB/CS (BMP-2/FGF-2) group. The expression of OC was consistent with ALP, which was higher in the APCB/(BMP-2/FGF-2) group compared with either BMP-2 or FGF-2 alone. OC expression was highest in the APCB/CS (BMP-2/FGF-2) group (Fig. 8C). These results are consistent with the results from the calcium content assay. In addition, FGF-2 promoted the expression of CD34 (a marker of new vessels) markedly (Fig. 8D). The levels of CD34 were higher in the APCB/(BMP-2/FGF-2) and APCB/CS (BMP-2/FGF-2) groups compared with other groups. This result suggested that the combination of rhBMP-2 and FGF-2 also had a synergetic effect on angiogenesis during osteogenic induction.

\section{Discussion}

BMP-2 is an osteogenic protein known to positively affect fracture healing and bone regeneration in both animals and humans. A major challenge of the use of BMP-2 clinically is associated with the supra-physiologic dose that is delivered by current formulations ( $>40 \mathrm{mg}$ ), leading to safety concerns. Low-dose FGF-2 further increases BMP-induced ectopic bone formation (23-25). This finding is consistent with the results of the present study; FGF-2 was involved in both early and late stage bone differentiation, and promoted bone regeneration by enhancing angiogenesis, especially in a rat ectopic bone formation model.

Due to the numerous signaling pathways involved in osteochondral repair, synergy between multiple growth factors to improve their clinical potential is an area of great interest (26). In the present study, western blotting results demonstrated that FGF-2 activated the phosphorylation of ERK1/2 in a dose-dependent manner. FGF-2 stimulated the phosphorylation of ERK1/2, p38 and JNK with or without the presence of 2 or $4 \mu \mathrm{g} / \mathrm{ml}$ rhBMP-2. Additionally, it was demonstrated that ERK MAPKs were involved in the promoting effect of FGF-2 on BMP-2-induced osteoblastic differentiation in C2C12 cells. Peak p-ERK1/2 levels were achieved following treatment with the combination of $4 \mu \mathrm{g} / \mathrm{ml} \mathrm{BMP-2}$ and $2 \mathrm{ng} / \mathrm{ml} \mathrm{FGF-2.} \mathrm{This}$ combination also affected the expression of early (BMP-2, BMP-4, ALP and RUNX2) and late (bone sialoprotein, COLL $\alpha 1$ and OC) osteoblast genes. In addition, the activation of p-JNK was not so significant between different treatment groups.

In vivo, low dose FGF-2 (2 ng) increased calcium deposition in the peroneus implants of rats significantly. In contrast, higher doses of FGF-2 resulted in less ectopic bone formation. According to our previous study using micro computed tomography analysis (27), mineral deposition was enhanced by BMP-2; i.e., there was higher bone mineral density, bone volume/total volume and trabecular thickness. The results of the calcium test revealed that the controlled simultaneous release of BMP-2 and FGF-2 using chitosan-coated APCB composite materials had the best effect on inducing osteogenesis. Histological and immunohistochemistry assays revealed that FGF-2 combined with BMP-2 heightened the expression of ALP, OC and CD34 significantly.

The results of the present study demonstrated that simultaneous local sustained administration of low-dose FGF-2 and BMP-2 increased angiogenesis and calcium deposition markedly in a rat ectopic implantation model, compared with administration of BMP-2 only. Their cooperative promotive roles in bone induction are served through the ERK signaling pathway and may have potential for bone regenerative therapeutics.

\section{Acknowledgements}

The present study was supported by the National Natural Science Foundation of China (grant no. 81273570), the 'Significant New Drugs Development' Project of Guangdong Province (grant no. 2013A022100033), the Guangzhou Science and Technology Plan Project (grant no. 201300000041) and National Natural Science Foundation of China (grant no. 31370974$)$.

\section{References}

1. Atluri K, Seabold D, Hong L, Elangovan S and Salem AK: Nanoplex-mediated codelivery of fibroblast growth factor and bone morphogenetic protein genes promotes osteogenesis in human adipocyte-derived mesenchymal stem cells. Mol Pharm 12: 3032-3042, 2015.

2. Charles LF, Woodman JL, Ueno D, Gronowicz G, Hurley MM and Kuhn LT: Effects of low dose FGF-2 and BMP-2 on healing of calvarial defects in old mice. Exp Gerontol 64: 62-69, 2015.

3. Du X, Xie Y, Xian CJ and Chen L: Role of FGFs/FGFRs in skeletal development and bone regeneration. J Cell Physiol 227: 3731-3743, 2012.

4. Fakhry A, Ratisoontorn C, Vedhachalam C, Salhab I, Koyama E, Leboy P, Pacifici M, Kirschner RE and Nah HD: Effects of FGF-2/-9 in calvarial bone cell cultures: Differentiation stage-dependent mitogenic effect, inverse regulation of BMP-2 and noggin, and enhancement of osteogenic potential. Bone 36 : 254-266, 2005.

5. Jeon O, Song SJ, Kang SW, Putnam AJ and Kim BS: Enhancement of ectopic bone formation by bone morphogenetic protein-2 released from a heparin-conjugated poly(L-lactic-co-glycolic acid) scaffold. Biomaterials 28: 2763-2771, 2007.

6. Jeong I, Yu HS, Kim MK, Jang JH and Kim HW: FGF2-adsorbed macroporous hydroxyapatite bone granules stimulate in vitro osteoblastic gene expression and differentiation. J Mater Sci Mater Med 21: 1335-1342, 2010.

7. Kaewsrichan J, Wongwitwichot P, Chandarajoti K, Chua KH and Ruszymah BH: Sequential induction of marrow stromal cells by FGF2 and BMP2 improves their growth and differentiation potential in vivo. Arch Oral Biol 56: 90-101, 2011.

8. Kawaguchi H, Jingushi S, Izumi T, Fukunaga M, Matsushita T, Nakamura T, Mizuno K, Nakamura T and Nakamura K: Local application of recombinant human fibroblast growth factor-2 on bone repair: A dose-escalation prospective trial on patients with osteotomy. J Orthop Res 25: 480-487, 2007.

9. Kyllönen L, D'Este M, Alini M and Eglin D: Local drug delivery for enhancing fracture healing in osteoporotic bone. Acta Biomater 11: 412-434, 2015.

10. Lei L, Wang S, Wu H, Ju W, Peng J, Qahtan AS, Chen C, Lu Y, Peng J, Zhang $X$ and Nie $\mathrm{H}$ : Optimization of release pattern of FGF-2 and BMP-2 for osteogenic differentiation of low-population density hMSCs. J Biomed Mater Res A 103: 252-261, 2015.

11. Li P, Bai Y, Yin G, Pu X, Huang Z, Liao X, Chen X and Yao Y: Synergistic and sequential effects of BMP-2, bFGF and VEGF on osteogenic differentiation of rat osteoblasts. J Bone Miner Metab 32: 627-635, 2014. 
12. Lisignoli G, Zini N, Remiddi G, Piacentini A, Puggioli A, Trimarchi C, Fini M, Maraldi NM and Facchini A: Basic fibroblast growth factor enhances in vitro mineralization of rat bone marrow stromal cells grown on non-woven hyaluronic acid based polymer scaffold. Biomaterials 22: 2095-2105, 2001.

13. Ma SY, Feng ZQ, Lai RF and Yin ZD: Synergistic effect of RhBMP-2 and bFGF on ectopic osteogenesis in mice. Asian Pac J Trop Med 8: 53-59, 2015.

14. Mukherjee A, Dong SS, Clemens T, Alvarez J and Serra R: Co-ordination of TGF-beta and FGF signaling pathways in bone organ cultures. Mech Dev 122: 557-571, 2005.

15. Nakamura $Y$, Tensho $K$, Nakaya $H$, Nawata $M$, Okabe $T$ and Wakitani S: Low dose fibroblast growth factor-2 (FGF-2) enhances bone morphogenetic protein-2 (BMP-2)-induced ectopic bone formation in mice. Bone 36: 399-407, 2005.

16. Perez RA, El-Fiqi A, Park JH, Kim TH, Kim JH and Kim HW: Therapeutic bioactive microcarriers: Co-delivery of growth factors and stem cells for bone tissue engineering. Acta Biomater 10: 520-530, 2014.

17. Katagiri T, Yamaguchi A, Komaki M, Abe E, Takahashi N, Ikeda T, Rosen V, Wozney JM, Fujisawa-Sehara A and Suda T: Bone morphogenetic protein-2 converts the differentiation pathway of $\mathrm{C} 2 \mathrm{C} 12$ myoblasts into the osteoblast lineage. J Cell Biol 127: 1755-1766, 1994.

18. Shields LB, Raque GH, Glassman SD, Campbell M, Vitaz T, Harpring $\mathrm{J}$ and Shields CB: Adverse effects associated with high-dose recombinant human bone morphogenetic protein-2 use in anterior cervical spine fusion. Spine (Phila Pa 1976) 31: $542-547,2006$
19. Shrivats AR, McDermott MC and Hollinger JO: Bone tissue engineering: State of the union. Drug Discov Today 19: 781-786, 2014.

20. Sun F, Pan Q, Wang J, Liu S, Li Z and Yu Y: Contrary effects of BMP-2 and ATRA on adipogenesis in mouse mesenchymal fibroblasts. Biochem Genet 47: 789-801, 2009.

21. Livak KJ and Schmittgen TD: Analysis of relative gene expression data using real-time quantitative PCR and the 2(-Delta Delta C(T)) method. Methods 25: 402-408, 2001.

22. Datta N, Holtorf HL, Sikavitsas VI, Jansen JA and Mikos AG: Effect of bone extracellular matrix synthesized in vitro on the osteoblastic differentiation of marrow stromal cells. Biomaterials 26: 971-977, 2005.

23. Tannoury CA and An HS: Complications with the use of bone morphogenetic protein 2 (BMP-2) in spine surgery. Spine J 14: 552-559, 2014.

24. Wang H, Zou Q, Boerman OC, Nijhuis AW, Jansen JA, Li Y and Leeuwenburgh SC: Combined delivery of BMP-2 and bFGF from nanostructured colloidal gelatin gels and its effect on bone regeneration in vivo. J Control Release 166: 172-181, 2013.

25. Wu S, Liu X, Yeung KW, Liu C and Yang X: Biomimetic porous scaffolds for bone tissue engineering. Mat Sci Eng 80: 1-36, 2014

26. Yuan Q, Kubo T, Doi K, Morita K, Takeshita R, Katoh S, Shiba T, Gong P and Akagawa Y: Effect of combined application of bFGF and inorganic polyphosphate on bioactivities of osteoblasts and initial bone regeneration. Acta Biomater 5: 1716-1724, 2009.

27. Zhang Y, Ma Y, Yang M, Min S, Yao J and Zhu L: Expression, purification, and refolding of a recombinant human bone morphogenetic protein 2 in vitro. Protein Expr Purif 75: 155-160, 2011. 